\title{
PALABRAS QUE ¿SOLO? HIEREN. REPETICIONES ABYECTAS Y RESIGNIFICACIONES LIBERADORAS
}

\author{
WORDS THAT - ONLY?- WOUND. ABJECT REPETITIONS AND \\ LIBERATING RESIGNIFICATIONS
}

\author{
Mónica Cano Abadía \\ Universidad de Zaragoza (España)
}

Recibido: 20-05-2012

Aceptado: 26-06-2012

Resumen: La performatividad de la filosofía de Judith Butler posibilita acciones transformadoras que resignifican categorías que, a menudo, se nos presentan como coercitivas e hirientes. Es el caso del lenguaje de odio y del insulto, que puede ser resignificado como lo fue el término queer, que pasó a ser una forma de autodenominación orgullosa. Reproducir performativamente las normas sociales crea sensación de estabilidad y de coherencia, pero Butler recoge la idea de iterabilidad de Derrida: siempre se abren brechas en la repetición que posibilitan resultados inesperados. Al repetir siempre introduciendo diferencias, las normas de género se ven modificadas y nunca son reproducidas de forma perfecta y definitiva.

Palabras-clave: Performatividad, resignificaciones positivas, iterabilidad, lenguaje de odio.

\begin{abstract}
Judith Butler's philosophy allows the existance of transforming actions that resignificate categories that, often, are presented to us as coercive and hurtful. That is the case of the hate speech and the insult, that can be resignificated the same way the term queer was, becoming a proud way to name oneself. Performatively reproducing social norms creates a sense of stability and coherence, but Butler follows the derridean idea of iterability: breaches are always open through repetition and they allow unexpected outcomes. By always introducing differences when we repeat, gender norms are always modified and never reproduced in a perfect and definitive way.
\end{abstract}

Key-words: Performativity, positive resignifications, iterability, hate speech. 
La performatividad es para Judith Butler un mecanismo cultural que nos hace surgir como sujetos reconocibles. Sexo, género, cuerpo, raza, psique, son categorías que se inscriben en nuestra subjetividad de forma performativa y que posibilitan nuestra emergencia como sujetos.

La dimensión lingüística de la performatividad para Butler es fundamental, ya que considera que el lenguaje es un proceso de significación. El lenguaje no sólo consiste en palabras orales o escritas, sino que también incluye todo vehículo que transmita significados y valores, tales como imágenes, gestos o estética corporal. El lenguaje produce significados y valores no a través de un acto único, sino mediante un proceso incesante que se basa en dos elementos básicos: la repetición y la exclusión. Ambos elementos configuran las líneas de la performatividad de Butler. Debemos imitar, citar incesablemente categorías, pero también, y al mismo tiempo, se nos indica qué no tenemos que repetir, qué tenemos que rechazar. Al configurarnos, constituimos también aquello que no somos; y lo excluido no es un exterior absoluto sino constitutivo, capaz de irrumpir en cualquier momento en nuestro interior, desestabilizando la coherencia de nuestras categorías.

Este proceso performativo, configurador de subjetividades, no es determinista sino que permite la capacidad de acción del sujeto construido. La repetición no es nunca mecánica, sino que abre espacio para el desplazamiento, pues no consigue nunca identidad. Butler recupera la concepción de iterabilidad de Jacques Derrida, como instancia que permite la apertura hacia la alteridad $^{1}$. A través de la iterabilidad, de la cita, la imitación, la repetición, se abre un espacio para lo nuevo. La repetición no es estanca, sino todo lo contrario: nunca es idéntica, siempre es imperfecta y siempre queda un espacio abierto para la actuación, para lo nuevo, para lo otro. En la repetición encontramos una posibilidad de aparición de lo diferente.

Así pues, es el propio proceso el que nos da las herramientas para ejercer la resistencia. El mismo proceso performativo, al basarse en la repetición, y al no ser nunca la repetición idéntica, crea una brecha a través de la cual la imperfección y la alteridad emergen, posibilitando así el cambio y la capacidad de resignificación de los procesos. Butler, en este sentido, coincide con la idea de Foucault de que la resistencia es interna al poder, de que resistencia y poder son contemporáneos y coextensivos. Para Butler, las categorías constriñen y realizan ejercicios de exclusión, pero al mismo tiempo proporcionan un lugar desde el cual se pueden resignificar positivamente los aspectos más intolerables de la categoría. La norma se puede desplazar, se pueden repetir de forma aberrante los modelos para multiplicarlos y permitir así la aparición de modelos alternativos.

[1] Véase: DERRIDA, "Firma, acontecimiento, contexto", en Márgenes de la filosofía, Madrid, Cátedra, 1989, pp. 347-372. 
El lenguaje, para Butler, nos pertenece pero se escapa de nuestro control; no es trascendente, pero nos excede en dos instancias: por un lado, el lenguaje está ya cuando llegamos al mundo, aprendemos un lenguaje que ya ha sido utilizado y contextualizado; por otra parte, aun cuando ya hemos aprendido a utilizarlo no lo controlamos completamente, no lo contenemos. Nuestra relación con el lenguaje es fluida, nunca cerrada. El lenguaje, en este sentido, es excitable ${ }^{2}$; el habla está fuera de nuestro control total.

La teoría del lenguaje de Butler se relaciona con su concepción del sujeto. El lenguaje nos excede, y el inconsciente es un lugar de exceso, un núcleo de opacidad que no podemos controlar. La opacidad de lo que somos se transmite también en el lenguaje. Para Butler, el sujeto es postsoberano: no es capaz de controlarlo todo, ya que ni siquiera es capaz de controlarse a sí mismo. Es un sujeto abierto, precario, vulnerable, dependiente de los demás, fluido, que se hace y se deshace, y que se sustenta en un núcleo de opacidad constitutivo. Este núcleo de opacidad no se revela y se resuelve, pero se manifiesta causando una inestabilidad en el sujeto.

Esta excitabilidad del lenguaje, esta inestabilidad del sujeto se manifiesta sobre todo en lo corporal, que es el lugar privilegiado de la manifestación de lo inconsciente. El cuerpo, para Butler, es performativo: el cuerpo se materializa a través de la performatividad y de ejes centrales como son sexo, género, raza, etc. El cuerpo no puede ser independiente del lenguaje: no son la misma instancia, pero no pueden existir el uno sin el otro. El cuerpo está siempre enredado en un proceso de significación que tiene que ver con el lenguaje desde el principio. No hay acceso posible al cuerpo si no es a través del lenguaje.

Butler a través de su concepción postsoberana del sujeto se opone a la idea del performativo divino o soberano, que se basa en la consideración moderna del sujeto. Butler considera que no se puede mantener una concepción soberana del sujeto ya que, siguiendo a Foucault, piensa que "el poder contemporáneo ya no goza de un carácter soberano"3. El poder fluye, lo atraviesa todo, y las personas ejercen y padecen a la vez el poder, y además el poder no se ejerce solamente desde un lugar, no emana de un sujeto soberano. Nos dice Butler: "el poder, difuminado a través de dominios dispares y en competencia dentro del aparato del Estado, también bajo formas difusas a través de la sociedad civil, no puede ser fácil ni definitivamente atribuido a un sujeto único que sea su "portavoz», ni a un representante soberano del Estado"4. Por otra parte, las

[2] Para ahondar en el concepto de excitabilidad del lenguaje véase: BUTLER, Lenguaje poder e identidad, Madrid, Editorial Síntesis, 1997. El título original en inglés es Excitable speech, haciendo referencia a un lenguaje que se excita.

[3] BUTLER, "Performativos soberanos", en Lenguaje, poder e identidad, Madrid, Editorial Síntesis, 1997, p. 129.

[4] Ibid., p. 135.

THÉMATA. Revista de Filosofía, № 48 julio-diciembre (2013) pp.: 217-225

doi: 10.12795/themata.2013.i48.19 
relaciones de poder tienen efectos múltiples: no sólo prohíben sino que también hacen emerger sujetos.

Butler se opone a la idea de que existe un sujeto previo, un sujeto puro no contaminado por el contexto cultural, sobre el cual se imponen las normas de género, sexo y sexualidad. Nos dice Butler: "En realidad, no hay «alguien» que acate una norma de género. Por el contrario, esta cita de la norma de género es necesaria para que a uno se lo considere como «alguien», para llegar a ser «alguien» viable, ya que la formación del sujeto depende de la operación

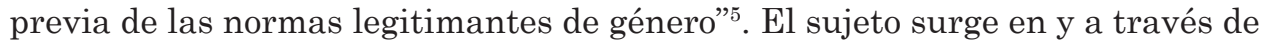
la repetición de las normas de género, por lo cual no existe un sujeto anterior a la cultura que pueda actuar de manera soberana.

La idea del performativo divino considera que el lenguaje es un vehículo a través del cual se manifiesta la voluntad de un sujeto soberano previo. El lenguaje realiza exactamente lo que el sujeto pretende. El sujeto controla el lenguaje y determina con él un mundo cerrado en el que las intenciones y los efectos se corresponden. Esta concepción considera el performativo como "eficaz, unilateral, transitivo y generativo"6. La performatividad de Butler se opone a la idea del performativo soberano, que se basa en la idea de un sujeto moderno soberano. El performativo no es divino, ni soberano: el lenguaje no es un dios todopoderoso que hace todo lo que la voluntad de la persona que emite pretende; el lenguaje no construye un mundo cerrado, acabado, no controla, no determina. Las palabras no hacen todo lo que dicen, ni realizan la intención del sujeto hablante. Dice Butler: "Que el lenguaje sea un tipo de acto no significa necesariamente que haga lo que dice; puede significar que expone o representa lo que dice al mismo tiempo que lo dice o, de hecho, en lugar de decirlo siquiera"7.

Para Butler, esta excitabilidad del lenguaje tiene una dimensión positiva: el lenguaje no nos controla. Los mensajes pueden ir en una dirección intencional, pero los efectos pueden ser imprevistos y contradictorios pues se reciben en contextos múltiples y se pueden utilizar de formas diversas. Una vez que nos comunicamos las palabras tienen su propia vida y no podemos controlar sus efectos. La dimensión perlocutiva del lenguaje es fundamental para Butler. Subraya que las palabras son equívocas, tienen significados y efectos plurales. De esta forma, es posible desconectar las palabras de las heridas. Esta perlocutividad de la performatividad abre otro posible espacio para la alteridad. Existen efectos imprevistos en los performativos que abren un espacio a la

[5] BUTLER, “Acerca del término «queer»", en Cuerpos que importan, Barcelona, Paidós, 2002, p. 326.

[6] BUTLER, "Performativos soberanos", op. cit., p 129.

[7] Ibid., p. 170.

THÉMATA. Revista de Filosofía, Nº48 julio-diciembre (2013) pp.: 217-225 doi: 10.12795/themata.2013.i48.19 
imprevisibilidad y que permiten que el lenguaje no controle todo significado y todo valor.

Butler analiza el lenguaje de odio, los actos de habla que hieren, como ejemplo de excitabilidad del lenguaje y de capacidad de resignificación de los discursos. Por lenguaje de odio se entiende un lenguaje o discurso que produce una herida.

Las personas reproducen los discursos de odio, pero no son la causa ni el origen, como pretende postular la concepción soberana de la performatividad. Para Butler, "si el poder ya no está constreñido por modelos de soberanía, si emana de un número indeterminado de "centros», ¿cómo vamos a encontrar el origen y causa del acto de poder mediante el cual se realiza la ofensa?". Sin embargo, hay quien sigue necesitando la idea de soberanía para pensar el poder como una instancia represora contra la cual actuar. Las tesis de Catherine MacKinnon y Mari Matsuda, que pretenden legislar contra el lenguaje de odio, mantienen esta noción de performativo soberano: la palabra es ya en sí misma una conducta hiriente, no hay forma de pronunciar esa palabra sin herir. No hay separación posible entre el efecto y la palabra, entre el acto de hablar y el acto de herir. Subrayan sobre todo la fuerza ilocutiva de la palabra: decir es hacer. La performatividad entendida así nos remite a una noción soberana de sujeto: un sujeto moderno, liberal, capaz de actuar soberanamente con sus actos de habla. Así pues, se considera que el sujeto que hiere con sus palabras, es un sujeto que elige herir con sus palabras, es un sujeto culpable, responsable del daño causado. Pero Judith Butler, al considerar que el lenguaje es performativo y que la repetición es parte fundamental de la performatividad, hace hincapié en la idea de que con el habla se repiten prácticas anteriores: "Esta visión de la performatividad implica que el discurso tiene una historia que no solamente precede, sino que además condiciona sus usos contemporáneos y que esta historia le quita efectivamente su carácter central a la visión presentista del sujeto según la cual éste es el origen o el propietario exclusivo de lo que se dice" 9 . Todo poder actúa repitiendo frases y formulaciones anterior y no hay, pues, un yo situado antes del discurso que actúa soberanamente a través del habla.

MacKinnon y Matsuda creen en la censura para acabar con el lenguaje de odio. Si las personas son responsables de pronunciar los discursos que hieren, basta con castigar a esas personas y no repetir las palabras hirientes para que el sexismo, el racismo, la homofobia, dejen de tener efectos en la sociedad. Sin embargo, Butler considera que estos problemas son estructurales, no individuales. Las personas reproducen las palabras que causan daño, pero no son ni la causa ni el origen. Las palabras ya tienen su historia antes de que sean

[8] Ibid., pp. 135-136.

[9] BUTLER, “Acerca del término «queer»", op. cit. P. 319.

THÉMATA. Revista de Filosofía, No 48 julio-diciembre (2013) pp.: 217-225

doi: 10.12795/themata.2013.i48.19 
emitidas. Los discursos tienen su vida propia en un contexto lingüístico que nos precede y que nos hace emerger como sujetos. Los discursos circulan, nos preceden y nos exceden. Así, Butler cree que no sólo hay que responsabilizar a las personas individuales, sino que el trabajo es más complejo y exige una multiplicidad de perspectivas que va más allá de legislar en contra de ciertos discursos. Butler no propone la censura sino la repetición como estrategia de resignificación de los discursos hirientes:

La exposición pública de la ofensa verbal es también una repetición, pero no se trata simplemente de eso, porque lo que se expone no es nunca exactamente lo mismo que lo que se quiere decir, y en esa afortunada inconmensurabilidad reside la oportunidad lingüística del cambio. Nunca nadie ha superado una injuria sin repetirla: su repetición es a la vez la continuación del trauma y aquello que marca una distancia dentro de la propia estructura del trauma, su posibilidad constitutiva de ser de otra manera. No existe la posibilidad de no repetir. La única cuestión que sigue planteándose es: ¿cómo se dará esa repetición, en un lugar jurídico o no; y a qué precio; y con qué esperanza? ${ }^{10}$.

\section{Término queer: del agravio a las posibilidades de emancipación}

Butler recurre al ejemplo del término queer como muestra de que el proceso performativo, entendido de forma no soberana, puede abrir espacios para la resignificación positiva. El término inglés queer ha significado tradicionalmente «extraño» o «inusual», pero hoy en día es utilizado a menudo para referirse a personas cuya orientación sexual y/o identidad de género o expresión de género no se conforma con las normas sociales heteronormativas.

A finales del siglo XX, el término fue utilizado con tono despectivo para denominar así a personas de las comunidades LGTBI. En los Estados Unidos de los años ochenta, en la era Reagan, se comenzó a fomentar la idea de que los homosexuales eran personas enfermas, vinculando directamente homosexualidad con la pandemia del SIDA:

No sólo se presenta la afección como la «enfermedad gay» sino que a través de la respuesta homofóbica e histérica a la enfermedad por parte de los medios se advierte una construcción táctica de continuidad entre la condición contaminada del homosexual (a consecuencia de la infracción de los límites que es la homosexualidad) y la enfermedad como una modalidad concreta de la contaminación homosexual ${ }^{11}$.

De manera que se comenzó a llamar queer a las lesbianas y los homosexuales para estigmatizarlos y vejarlos, y además: "Cuando el término se utilizaba como un estigma paralizante, como la interpelación mundana de una sexualidad patologizada, el usuario del término se transformaba en el emblema y el vehículo de la normalización y el hecho de que se pronunciara esa palabra constituía la regulación discursiva de los límites de la legitimidad"12.

[10] Ibid., p. 170.

[11] BUTLER, El género en disputa, op. cit., p. 259.

[12] BUTLER, "Acerca del término «queer»", op. cit., p. 313.

THÉMATA. Revista de Filosofía, Nº 48 julio-diciembre (2013) pp.: 217-225 doi: 10.12795/themata.2013.i48.19 
Las connotaciones de la palabra, sin embargo, cambiaron sustancialmente desde el seno de las comunidades LGTBI. Paul Goodman escribió en 1969 The Politics of Being Queer ${ }^{13}$, obra que tuvo un efecto significativo en los comienzos del movimiento de liberación gay en los Estados Unidos, especialmente al devenir un movimiento más radical en los años 80 y 90 . En la década de los 90s, comenzaron casi de manera espontánea a autodenominarse queer, para demostrar que sí, que eran homosexuales, o lesbianas, o bisexuales, pero no eran personas abyectas ni enfermas. Recuperan el término con el cual se les calificaba peyorativamente y se acogen bajo él, resignificándolo y dotándolo de una fuerza política y estratégica.

El efecto performativo buscado por la palabra inicialmente era causar daño y estigmatizar a unas determinadas personas. El propósito del uso de este término era avergonzar y producir un sujeto humillado, patologizado. Pero este efecto performativo inicial falló, y en el espacio que quedó abierto, en la falla del sistema performativo de los enunciados de género, se posibilitó una resignificación positiva del término. El término queer devino una categoría bajo la cual pudieron acogerse multitud de personas, ya no solamente lesbianas $\mathrm{u}$ homosexuales, sino muchas otras que tenían una concepción del género, el sexo o las sexualidades que no se correspondía con la comúnmente aceptada por la sociedad. Hoy en día, algunas personas utilizan queer como un término paraguas con un significado sociopolítico que unifica personas gays, lesbianas, trans, intersexuales, asexuales, autosexuales y personas heterosexuales que se sitúan fuera de los roles habituales dentro de una pareja heterosexual (practicantes de BDSM o poliamoristas, por ejemplo). Dice Butler: "En realidad, el término queer mismo fue precisamente el punto de reunión de las lesbianas y los hombres gay más jóvenes y, en otro contexto, de las intervenciones lesbianas y, todavía en otro contexto, de los heterosexuales y bisexuales para quienes el término expresa una afiliación con la política antihomofóbica" ${ }^{14}$.

Para Judith Butler el término queer es un ejemplo práctico y vivencial de cómo la performatividad puede abrir espacios de acción y le interesa sobre todo analizar la temporalidad del término: el giro que ha experimentado, su refundimiento y su resignificación. Butler retoma la idea de Nietzsche de cadena significante, que se ve reflejada en la consideración de Foucault del poder discursivo, para atender a la historia de un concepto, de un discurso. Con respecto al término queer, le interesa ver cómo ha pasado de ser un agravio que arroja a las personas a la abyección a ser un lugar resignificado positivamente desde el cual poder articular una oposición colectiva contra las normas de género, sexo y sexualidades.

[13] GOODMAN, "The politics of being queer", en Taylor Stoehr (ed.), Nature Heals: The Psychological Essays of Paul Goodman, New York, Free Life Editions, 1977, pp. 216-225.

[14] BUTLER, “Acerca del término «queer»", op. cit., p. 323.

THÉMATA. Revista de Filosofía, № 48 julio-diciembre (2013) pp.: 217-225

doi: 10.12795/themata.2013.i48.19 
La temporalidad del término queer no se termina con el significado subversivo que ha adquirido. Butler nos previene de que el uso de queer como concepto identitario tiene los mismos peligros de ejercer exclusión que el resto de términos. Se hace necesaria, entonces, una autocrítica dentro del activismo queer. Para tratar de evitar la exclusión que todo concepto conlleva, el término queer ha de seguir siendo un concepto que no es poseído sino que se usa, se tuerce, se desvía, se orienta, expandiéndose. Así, podrá ser un lugar de oposición colectiva y el punto de partida para reflexiones y actuaciones en el seno del activismo.

Se hace necesaria, desde la perspectiva de Butler y del feminismo queer, la crítica constante de todas las categorías de identidad, sin excepción. Todas las identidades necesitan una continua reelaboración dentro del discurso político. Pero esta crítica a las categorías de identidad no debe llevar hacia el inmovilismo o la negatividad, sino que ha de servir para analizar las relaciones de poder que genera el uso de la propia categoría. Dice Butler: "La desconstrucción política de lo «queer» no tiene por qué paralizar el empleo de tales términos, sino que, idealmente, debería extender su alcance y hacernos considerar a qué precio y con qué objetivos se emplean los términos y a través de qué relaciones de poder se engendraron tales categorías" ${ }^{15}$.

Judith Butler considera que es necesaria la existencia de categorías, pues son marcas que nos constituyen, sin las cuales no podríamos emerger como sujetos viables y reconocibles. Sin embargo, insiste en evidenciar la contingencia del término queer, así como la de todas las categorías de identidad:

La generalización temporal que realizan las categorías de identidad es un error necesario. Y si la identidad es un error necesario, entonces será necesario afirmar el término "queer» como una forma de afiliación, pero hay que tener en cuenta que también es una categoría que nunca podrá describir plenamente a aquellos a quienes pretende representar ${ }^{16}$.

Para terminar, querría hacer hincapié en el proceso de resignificación positiva que se ha desarrollado con el término queer, claro ejemplo de cómo la repetición aberrante, en contextos inesperados, puede ayudar a la liberación de ciertas categorías cuya intencionalidad, en un principio, parecía ser la de ejercer violencia sobre ciertas identidades y herir a ciertas personas. En palabras de Judith Butler:

Una ocupación o reterritorialización de un término que fue empleado para excluir a un sector de la población puede llegar a convertirse en un sitio de resistencia, en la posibilidad de una resignificación social y política capacitadora. Y, en cierta medida, esto es lo que ocurrió con la noción de queer. La aceptación contemporánea del término hace que la prohibición y la degradación inviertan su sentido, engendra un nuevo orden de valores, una afirmación política que parte de ese mismo término y se desarrolla a través de ese mismo término que en su acepción anterior tuvo como objetivo último erradicar precisamente tal afirmación ${ }^{17}$.

[15] Ibíd., p. 322.

[16] Ibid., p. 323.

[17] Ibid., p. 325.

THÉMATA. Revista de Filosofía, Nº48 julio-diciembre (2013) pp.: 217-225 doi: 10.12795/themata.2013.i48.19 


\section{Bibliografía}

Austin, John Langshaw, Cómo hacer cosas con palabras: palabras y acciones, Barcelona, Paidós, 1996.

Butler, Judith, "Performativos soberanos", en Lenguaje poder e identidad, Madrid, Editorial Síntesis, 1997, pp. 126- 173.

Butler, Judith, "Acerca del término «queer»", en Cuerpos que importan, Barcelona, Paidós, 2002, pp. 313-339.

Butler, Judith, El género en disputa. El feminismo y la subversión de la identidad, Barcelona, Paidós, 2007.

Derrida, Jacques, "Firma, acontecimiento, contexto", en Márgenes de la filosofía, Madrid, Cátedra, 1989, pp. 347-372.

Goodman, Paul, "The politics of being queer", en Taylor Stoehr (ed.), Nature Heals: The Psychological Essays of Paul Goodman, New York, Free Life Editions, 1977, pp. 216-225.

THÉMATA. Revista de Filosofía, №48 julio-diciembre (2013) pp.: 217-225

doi: 10.12795/themata.2013.i48.19 